\title{
A case of functional non communicating rudimentary horn of unicornuate uterus presenting as persistent lump abdomen
}

\author{
Sana Amrin*, Shobha Mukherjee, Usha Jain
}

Department of Obstetrics \& Gynaecology, Rohilkhand Medical College and Hospital Bareilly, Uttar Pradesh, India

Received: 6 October 2015

Revised: 2 December 2015

Accepted: 16 January 2016

\section{*Correspondence:}

Dr. Sana Amrin,

E-mail: sana_amrin07@yahoo.in

Copyright: (C) the author(s), publisher and licensee Medip Academy. This is an open-access article distributed under the terms of the Creative Commons Attribution Non-Commercial License, which permits unrestricted non-commercial use, distribution, and reproduction in any medium, provided the original work is properly cited.

\begin{abstract}
Unicornuate uterus with a functional non communicating rudimentary horn is a rare congenital mullerian duct anomaly. It presents with various complaints like dysmenorrhoea, hematometra, endometriosis, lump in abdomen, infertility and even ectopic pregnancy. Here we present such a case which had undergone exploratory laparotomy in the past for lump in abdomen and now presented to us with persistence of lump even after surgery.
\end{abstract}

Keywords: Unicornuate uterus, Functional non communicating rudimentary horn

\section{INTRODUCTION}

The incidence of unicornuate uterus is rare among all Mullerian duct anomalies. The incidence of Mullerian duct anomalies range between 0.4 to $10 \% .^{1}$ Its results from arrested development of one of the two Mullerian ducts. It is divided into four subgroups, type II b is presence of rudimentary horn with a non-communicating cavity. Most rudimentary horn are non-communicating $(90 \%) .^{2}$ It is generally considered that the presence of non-communicating cavitatory rudimentary horn (Buttram and Gibbons class II A, B) carries a poor reproductive prognosis and increases the risk of endometriosis and cornual pregnancy. ${ }^{3}$ The treatment is excision of rudimentary horn. This report describes such a case whose symptoms persisted even after a previous surgery.

\section{CASE REPORT}

A 23 year old nulligravida, married for 8 months, presented with complains of progressive pain and lump abdomen since menarche. She also gave history of being operated in the past 3 years ago for the same complaints. She had no records of the said operation but on further questioning it seemed to be an adnexectomy for haematosalpinx. Menarche attained at 14 year of age, cycles 3/30 days, regular with decreased flow and congestive dysmenorrhoea.

On general physical examination, she seemed to be mildly pale, rest normal.

On per abdominal examination vertical midline scar seen along with 18-20 weeks midline mass arising from pelvis, firm in consistency with restricted mobility.

On per speculum examination, cervix and vagina were healthy. Os was single and appeared nulliparous.

On $\mathrm{P} / \mathrm{V}$, the same mass appeared to be in continuation with uterus and adnexa seemed free. P/R confirmed P/V findings.

TVS showed a bicornuate uterus with hematometra of left uterine horn. Patient underwent exploratory laparotomy 
for resection of rudimentary horn. Intraoperative findings included apart from hematometra, cystic right ovary and omental adhesions on right tube. The left tube and ovary were absent (having been removed earlier for hematosalpinx). The rudimentary horn was $15 \times 10 \times 7 \mathrm{~cm}$ in size and cut section showed old altered blood.

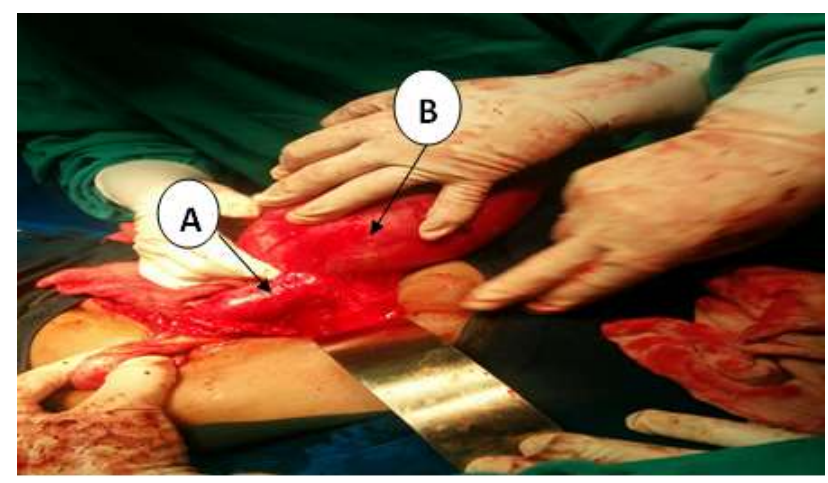

Figure 1: Showing (A) Right side normal size uterus, (B) Left side rudimentary horn with haematometra.

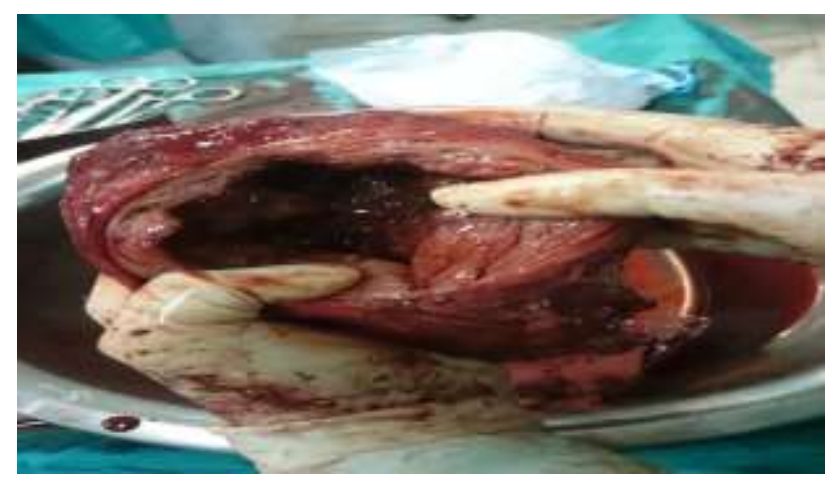

Figure 2: Showing cut section of rudimentary horn.

HPE findings confirmed hematometra. Patient withstood procedure well and had an uneventful post-operative period.

\section{DISCUSSION}

The incidence of mullerian duct anomalies range between 0.4 to $10 \%$. $^{1}$

American fertility society ${ }^{4}$ puts unicornuate uterus in class II and further sub divides it into

IIa - Rudimentary horn with cavity communicating to unicornuate uterus.

IIb - With cavity non-communicating.

IIc - With no cavity.

IId - With no rudimentary horn.

Incidence of unicornuate uterus is not well defined because patient can be asymptomatic or suffer from various symptoms like dysmenorrhoea, abdominal lump, chronic pelvic pain, infertility, endometriosis, hematometra, acute abdomen and ectopic pregnancy. Raga et $\mathrm{al}^{5}$ evaluated the incidence as between $0.2 \%$ in fertile and $0.6 \%$ in infertile. Most rudimentary horns are non-communicating $(90 \%){ }^{2}$

This report describes a rare case of functional non communicating horn of unicornuate uterus who presented as persistent lump and pain in abdomen even after undergoing exploratory laparotomy in the past for same complaints. She had undergone an adnexectomy for hematosalpinx in the past without removal of rudimentary horn. This exacerbated her symptoms of hematometrapost-surgery. So much so that she was even willing to undergo hysterectomy for such severe symptoms. Literature reveals 2 such cases in the past. One in Japan $^{6}$ and another in India. ${ }^{7}$

Therefore, knowledge of mullerian anomalies is essential for patient management especially in young nulliparous girls with dysmenorrhoea because misdiagnosis and wrong treatment can severely impact a patient's quality of life.

Funding: No funding sources

Conflict of interest: None declared

Ethical approval: Not required

\section{REFERENCES}

1. Byrne J, Nussbaum-Blask A, Taylor WS. Prevalence of mullerian duct anamolies detected at USG. Am J Med Genet. 2000;94(1):9-12.

2. O'leary JL, O'Leary JA. Rudimentary horn pregnancy. Obstet Gynecol. 1963;22:37.

3. Fedele L, Marchini M, Baglioni A, Carinelli S, Zamberletti D, Candiani GB. Endometrium of cavitatory rudimentary horns in unicornuate Uteri. Obstet Gynaecol March. 1990;75(3):437-40.

4. American Fertility Society: classification of mullerian anomalies. Fertil Steril. 1988;49:944.

5. Raga F, Bauset C, Remohi J, Bonilla-Musoles F, Simón C, Pellicer A. Reproductive impact of congenital mullerian anomalies. Hum Reprod. 1997;12:2277-81.

6. Tanaka Y, Hironori A, Hiroshi U, Maruyama T, Kuji $\mathrm{N}$, Sueoka K. Case of iatrogenic dysmenorrhoea in non-communicating rudimentary uterine horn and its laparoscopic resection. J Obstet Gynaecol Res. 2005;31(3):242-6.

7. Kriplani A, Agarwal N. Hysteroscopic and laparoscopic guided mini access hemihysterectomy for non-communicating uterine horn. Arch Gynecol Obstet. 2001;265:162-4.

Cite this article as: Amrin S, Mukherjee S, Jain U. A case of functional non communicating rudimentary horn of unicornuate uterus presenting as persistent lump abdomen. Int J Reprod Contracept Obstet Gynecol 2016;5:530-1. 